\title{
Obstetrical management of cancer in pregnancy and risk of adverse pregnancy and neonatal outcomes: a nationwide cohort study
}

\author{
Iben Greiber ${ }^{1}$, Jakob Viuff ${ }^{2}$, Lene Mellemkjær ${ }^{2}$, Cristel Hjortsh $ø j^{1}$, Ojvind Lidegaard ${ }^{1}$, \\ Lone Storgaard $^{1}$, and Mona Karlsen ${ }^{1}$ \\ ${ }^{1}$ Rigshospitalet \\ ${ }^{2}$ Danish Cancer Society Research Center
}

September 25, 2021

\begin{abstract}
Objectives. To investigate the obstetrical management of cancer in pregnancy and to determine adverse pregnancy and neonatal outcomes. Design. A register-based nationwide historical prospective cohort study. Setting and population. We assessed all pregnancies $(\mathrm{N}=4,071,848)$ in Denmark from 1 January 1973 to 31 December 2018. Methods. We linked data on maternal cancer, obstetrical, and neonatal outcomes. Exposure was defined as pregnancies exposed to maternal cancer $(\mathrm{n}=1,068)$. The control group comprised pregnancies without cancer. The groups were compared using logistic regression analysis and adjusted for potential confounders. Main outcome Measures. The primary outcome was the iatrogenic termination of the pregnancy (induced abortions/labor induction or elective caesarean section). Secondary outcomes were adverse neonatal outcomes. Results. More women with cancer in pregnancy, as compared to the control group, experienced first-trimester induced abortion; adjusted odds ratio (aOR) 3.7 (95\% CI 2.8-4.7), second-trimester abortion; aOR 9.0 (6.4-12.6), iatrogenic preterm delivery; aOR 10.9 (8.1-14.7), and iatrogenic delivery below 32 gestational weeks; aOR 16.5 (8.5-32.2). Neonates born to mothers with cancer in pregnancy had a higher risk of respiratory distress syndrome; aOR 1.5 (1.2-2.0), but not of low birth weight; aOR 0.6 (0.4-0.8), admission to neonatal intensive care unit more than seven days; aOR 1.4 (1.1-1.9), neonatal infection; aOR 0.9 (0.5-1.5) nor neonatal mortality; aOR1.3 (0.6-2.6). Conclusion. Cancer in pregnancy implies an increased risk of iatrogenic termination of pregnancy and iatrogenic premature birth. Neonates born to mothers with cancer in pregnancy had no increased risk of severe adverse neonatal outcomes.
\end{abstract}

\section{Hosted file}

Cancer in Pregnancy_Greiber_BJOG.docx available at https://authorea.com/users/437496/ articles/539090-obstetrical-management-of-cancer-in-pregnancy-and-risk-of-adversepregnancy-and-neonatal-outcomes-a-nationwide-cohort-study 


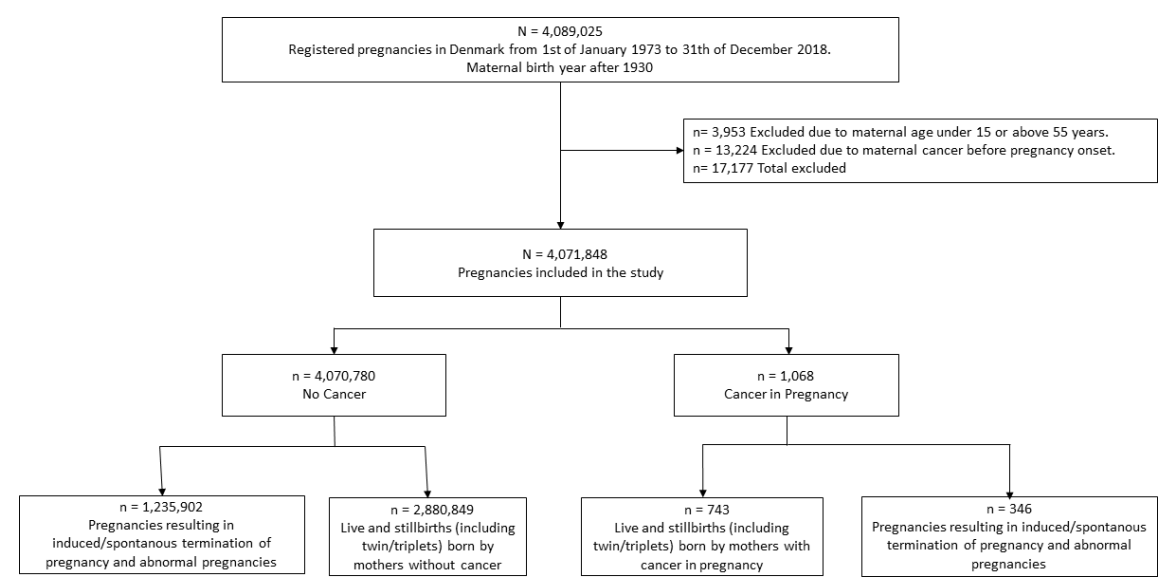

\section{Hosted file}

BJOG_table1.docx available at https://authorea.com/users/437496/articles/539090-obstetricalmanagement-of-cancer-in-pregnancy-and-risk-of-adverse-pregnancy-and-neonatal-outcomes-anationwide-cohort-study

\section{Hosted file}

BJOG_table2.docx available at https://authorea.com/users/437496/articles/539090-obstetricalmanagement-of-cancer-in-pregnancy-and-risk-of-adverse-pregnancy-and-neonatal-outcomes-anationwide-cohort-study

\section{Hosted file}

BJOG_table 3.docx available at https://authorea.com/users/437496/articles/539090-obstetricalmanagement-of-cancer-in-pregnancy-and-risk-of-adverse-pregnancy-and-neonatal-outcomes-anationwide-cohort-study 